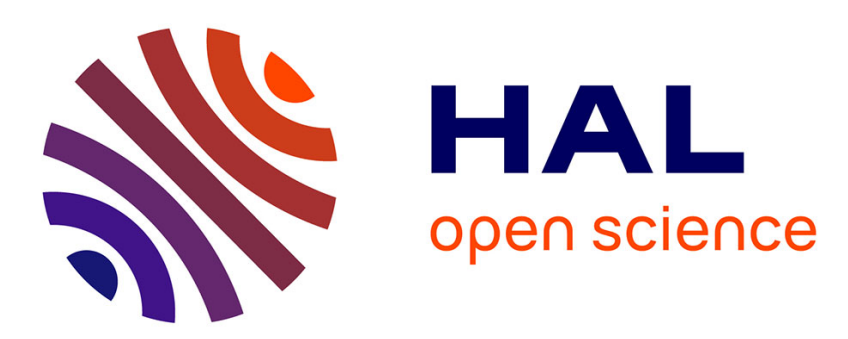

\title{
Unsaturated polyester resins: numerical solution of a system of equations able to describe both styrene and unsaturation consumption
}

\author{
Ramiro Dell'Erba
}

\section{To cite this version:}

Ramiro Dell'Erba. Unsaturated polyester resins: numerical solution of a system of equations able to describe both styrene and unsaturation consumption. Journal of Applied Polymer Science, 2000, 78 (1), pp.124-132. 10.1002/1097-4628(20001003)78:13.0.CO;2-H . hal-01998478

\section{HAL Id: hal-01998478 https://hal.science/hal-01998478}

Submitted on 18 Mar 2019

HAL is a multi-disciplinary open access archive for the deposit and dissemination of scientific research documents, whether they are published or not. The documents may come from teaching and research institutions in France or abroad, or from public or private research centers.
L'archive ouverte pluridisciplinaire HAL, est destinée au dépôt et à la diffusion de documents scientifiques de niveau recherche, publiés ou non, émanant des établissements d'enseignement et de recherche français ou étrangers, des laboratoires publics ou privés. 


\section{ENEA}

Italian National Agency for New Technologies, Energy and Sustainable Economic Development

http://www.enea.it/en

http://robotica.casaccia.enea.it/index.php?lang=en

This paper is a pre-print. The final paper is available on: Journal of Applied Polymer Science " Unsaturated polyester resins:

numerical solution of a system of equations able to describe both styrene and unsaturation consumption" R. dell'Erba. V. 78, pg.

124-132 (2000). 


\title{
Unsaturated polyester resins: numerical solution of a system of equations able to describe both styrene and unsaturation consumption
}

\author{
by \\ Ramiro dell'Erba ${ }^{1}$
}

${ }^{1}$ Istituto di Ricerca e Tecnologia delle Materie Plastiche - C.N.R., Via Toiano 6, 80072 Arco Felice (Napoli), Italy. 
Key Words: Polyester; resin; curing; numerical; modeling. 


\section{SUMMARY}

In this paper, a numerical solution of a system of differential equations is proposed, able to describe the kinetic curing of a polyester resin in a temperature range between 336 ${ }^{\circ} \mathrm{K}$ up to $363^{\circ} \mathrm{K}$.

The conversion degree of both styrene and polyester unsaturations were experimentally measured, in a preceding paper, by Fourier Transform Infrared Spectroscopy; now we describe a more precise and correct theoretical calculation of the kinetic reactions relative to the experiments described in that previous paper. This new calculation is based on the solution of the kinetic equations, based on free radicals polymerisation reaction, instead of empirical formulas. The obtained results, relative to the conversion degree of both the components, show better agreement with the experimental values, both with respect to the usual kinetic model and also compared with a new empirical model that we proposed in the previous paper, to fit the same set of experimental data. The comparison between the models was performed by hypothesis test.

The parameters that characterise the propagation reactions were found to increase with increasing temperature, according to an Arrhenius law, leading to an activation energy between $(98 \pm 2) \mathrm{KJ} / \mathrm{mol}$ for the styrene and $(110 \pm 2) \mathrm{KJ} / \mathrm{mol}$ for polyester unsaturation, in the temperature range examined.

We conjecture this system could be useful to monitor for each time, the consumption of the different species present in the kinetic reaction, and to refine the final thermomechanical properties of the resins. 


\section{1 - INTRODUCTION}

In a preceding paper [1] a kinetic analysis of a commercial grade unsaturated polyester (UPE) was carried out in the temperature range from $336^{\circ} \mathrm{K}$ up to $363^{\circ} \mathrm{K}$. The experimental technique used to measure, in real time, the consumption of reactive species in the system, was Fourier Transform Infrared Spectroscopy (FTIR). The principal advantages of this technique are the ability in detecting different functional groups resulting in the monitoring of both the styrene (ST) and the polyester unsaturations (PU) conversion. Moreover sensitivity, optical stability and high data collection rate are furthermore advantages of the FTIR technique.

Unsaturated polyesters (UPE) are one of the most used thermosetting materials, owing to their low cost and relatively good mechanical properties. They are employed in a broad range of products, such as the automotive industries and building industries. Generally UPE are prepared by condensation reactions of saturated and unsaturated dicarboxilic acids (or anhydride) with glycol and dilution with unsatured monomers like styrene (ST); qualitative and quantitative variations in these components lead to a wide range of possibilities for the characteristics of the final products. This is one of the reasons why the UPE have so much success in many applications. Moreover the development of injection techniques, like bulk moulding compound (BMC), sheet moulding compound (SMC), has given more impulse to the commercial expansion of UPE, because the well known possibility, in realisation of complex pieces, offered by these techniques.

From these arguments arises the need to control this enormous variability, by a better understanding of the reactions kinetics during cure, and their complex flow behaviour during injection. Many papers address the final products from an engineering point of view, while a few papers [2, 3, 4] studied the whole conversion process, step by step; they generally used the approach describing the curing reaction as a simple free radical homopolymerization [5, 6, 7], with no differentiation between the reactivity of ST and polyester double bonds. This simplified reaction scheme could be useful to describe the overall kinetic curing, monitored by Differential Scanning Calorimetry (DSC), with no possibility to distinguish the different species involved. It cannot give us detailed information on the reaction mechanism, i.e., cannot be useful to describe how the kinetics curing is affected by the parameters involved, and which of these parameters is really 
important. On the contrary a differentiation of the involved species can be investigated by FTIR.

In this paper we numerically solve a simplified form of a system of differentials equations, describing the evolution, with time and temperature, of the reactive species; particular attention was posed to describe the separate kinetics of styrene and polyester unsaturations. We find the solutions have general validity, but the materials parameters involved in the system were estimated to fit a set of experimental data in the temperature range from $336^{\circ} \mathrm{K}$ up to $363^{\circ} \mathrm{K}$.

The final goal will result in a complete description for each time and temperature of the degree of consumption of the species PU, ST and others species involved in the model of the kinetic reaction. 


\section{2 - EXPERIMENTAL}

\section{1 - Materials}

As outlined in the introduction, the experimental data used in the present paper are the same as from reference [1]; so the only work executed was a computational one. For any details regarding the uncured unsaturated polyester resin, see the previous reference [1].

\section{2 - Position of the problem}

This section describes a precise definition of the physical quantities needed to describe the kinetic reactions, with the simplified assumptions.

Under the hypothesis of free radicals reactions, the curing reaction of UPE requires chemical initiator, I, able to generate free radicals to start the polymerisation reaction. Afterwards the reactions continue, characterised by reaction constant $\mathrm{k}_{\mathrm{p}}$. Moreover, according to the literature [10], the gelification phenomena lead to a diffusion controlled reaction. This last step cannot be taken in account by the usual equations to describe the degree of monomer conversion, $\alpha$. One of the most used equation to describe the $\alpha$ evolution is $[1,9,10]$ :

$$
\frac{d \alpha(t)}{d t}=\left(k_{1}+k_{2} \alpha^{m}\right)(1-\alpha)^{n},
$$

where $\alpha$ is the monomer degree of conversion defined by

$$
\alpha(t)=\frac{1-[M](t)}{[M]_{0}},
$$

$[\mathrm{M}]$ being the monomer concentration of initial value $[\mathrm{M}]_{0} ; \mathrm{k}_{1}, \mathrm{k}_{2}, \mathrm{~m}$, and $\mathrm{n}$ are empirical parameters. The square brackets have the meaning of a concentration, expressed in $g /(m o l * L)$.

In this case, there are two monomeric species, PU and ST so we have two conversion factors, $\alpha_{1}$ and $\alpha_{2}$ :

$$
\alpha_{1}(t)=\frac{1-[P U](t)}{[P U]_{0}}
$$

and 


$$
\alpha_{2}(t)=\frac{1-[S T](t)}{[S T]_{0}}
$$

If we suppose that free radical polymerisation can describe the reaction of the single component we can simplify the reactions by the following scheme:

1) The initiator, I, decompose to a radical initiator I*.

2) The radical I* reacts with ST and PU to form a styrene radical ST* and UP* respectively.

3) These radicals, $\mathrm{ST}^{*}$ and $\mathrm{PU}$, can react with $\mathrm{ST}$ and PU monomers to form radicals of larger size by propagation and transferring reactions in which the reactivity is transferred.

4) When two radicals react they link by covalent bond and the resulting product cannot participate the reactions anymore; these are termination reactions.

5) The decrease of the number of free radicals has another cause: the presence of reactor inhibitor $Z$. The need of its presence lies in the necessity to prevent premature curing of the resins.

Each one of the chemical reactions described in the step 1-5 can be schematised by a typical rate constant. These reactions can be collected in classes to describe the modality of the reaction, if we assume that their rates are not dependant on the molecular weight of the involved species [11].

So far, the dissociation reactions, characterised by the constants $k_{d}$, transferring reactions, $k_{t}$, propagation reactions, $k_{p}$, ending reactions, $k_{e}$ and inhibition reactions, $k_{z}$ are distinguished.

So we have four reactant species (I, Z, PU, ST) and their radicals (I*, PU*, ST*) with the exception of the inhibitor $\mathrm{Z}$. The five steps can be described by the following chemical formulas; for the step 1:

$$
[I] \stackrel{k_{d 1}}{\longrightarrow} 2\left[I^{*}\right] .
$$

For the PU they are (step 2 and step 3):

$$
\begin{aligned}
& {[P U]+\left[I^{*}\right] \stackrel{k_{d 2}}{\longrightarrow}\left[P U^{*}\right],} \\
& {[P U]+\left[P U^{*}\right] \stackrel{k_{t 1}}{\longrightarrow}\left[P U^{*}\right],} \\
& {[P U]+\left[S T^{*}\right] \stackrel{k_{t 4}}{\longrightarrow}\left[P U^{*}\right] .}
\end{aligned}
$$


The same reactions can be written for the ST, with different rate constants (step 2 and step 3).

$$
\begin{aligned}
& {[S T]+\left[I^{*}\right] \stackrel{k_{d 3}}{\longrightarrow}\left[S T^{*}\right],} \\
& {[S T]+\left[S T^{*}\right] \stackrel{k_{t 2}}{\longrightarrow}\left[S T^{*}\right],} \\
& {[P U]+\left[S T^{*}\right] \stackrel{k_{t 3}}{\longrightarrow}\left[S T^{*}\right] .}
\end{aligned}
$$

The termination reactions between the radicals: some radicals can terminate by coupled termination with covalent bonds and loss of radical activity (step 4).

$$
\begin{aligned}
& {\left[P U^{*}\right]+\left[P U^{*}\right] \stackrel{k_{e 1}}{\longrightarrow}\left[P U^{*}\right],} \\
& {\left[S T^{*}\right]+\left[S T^{*}\right] \stackrel{k_{e 2}}{\longrightarrow}\left[S T^{*}\right],} \\
& {\left[P U^{*}\right]+\left[S T^{*}\right] \stackrel{k_{e 3}}{\longrightarrow}\left[P U^{*}\right],}
\end{aligned}
$$

with loss of one radical activity.

Finally the inhibitor $\mathrm{Z}$ can react only with radicals (step 5).

$$
\begin{aligned}
& {[Z]+\left[I^{*}\right] \stackrel{k_{z 1}}{\longrightarrow}[I],} \\
& {[Z]+\left[S T^{*}\right] \stackrel{k_{z 2}}{\longrightarrow}[S T],} \\
& {[Z]+\left[P U^{*}\right] \stackrel{k_{23}}{\longrightarrow}[P U] .}
\end{aligned}
$$

This is the scheme of all the considered reactions. We outlined 7 reactant species (I, Z, $\left.\mathrm{PU}, \mathrm{ST}, \mathrm{I}^{*}, \mathrm{PU}^{*}, \mathrm{ST}^{*}\right)$, and 13 rate constants ( $k_{d 1}, k_{d 2}, k_{d 3}, k_{t 1}, k_{t 2}, k_{t 3}, k_{t 4}, k_{e 1}, k_{e 2}, k_{e 3}, k_{\mathrm{z} 1}, k_{\mathrm{z} 2}$, $\left.k_{z 3}\right)$. Note, once again, that we have assumed the rate constants do not depend on the molecular weight of each of the species, in order to obtain a kinetic expression for the overall rate of polymerisation [11]. So far the rate of consumption of the monomer correspond to the growing rate of the building polymer.

By these assumptions, the following differential equations can be written to describe the reactions:

$$
\frac{d[I]}{d t}=-\frac{1}{2} k_{d 1}[I],
$$




$$
\begin{aligned}
& \frac{d[P U]}{d t}=-k_{d 2}[P U]\left[I^{*}\right]-k_{t 1}[P U]\left[P U^{*}\right]-k_{t 4}[S T]\left[S T^{*}\right], \\
& \frac{d[S T]}{d t}=-k_{d 3}[S T]\left[I^{*}\right]-k_{t 2}[S T]\left[S T^{*}\right]-k_{t 3}[S T]\left[P U^{*}\right], \\
& \frac{d[Z]}{d t}=-[Z]\left(k_{z 1}\left[I^{*}\right]+k_{z 2}\left[S T^{*}\right]+k_{z 3}\left[P U^{*}\right]\right), \\
& \frac{d\left[I^{*}\right]}{d t}=-\frac{1}{2} k_{d 1}[I]-k_{d 2}[P U]\left[I^{*}\right]-k_{d 3}\left[I^{*}\right][S T]-k_{z 1}\left[I^{*}\right][Z], \\
& \frac{d\left[P U^{*}\right]}{d t}=-\frac{1}{2} k_{d 2}\left[I^{*}\right][P U]+k_{t 4}\left[P U^{*}\right]\left[S T^{*}\right]-k_{t 3}[S T]\left[P U^{*}\right]- \\
& \quad k_{e 2}\left[P U^{*}\right]^{2}-k_{e 3}\left[P U^{*}\right]\left[S T^{*}\right]-k_{z 2}\left[P U^{*}\right][Z], \\
& \frac{d\left[S T^{*}\right]}{d t}=-\frac{1}{2} k_{d 3}\left[I^{*}\right][S T]-k_{t 4}[P U]\left[S T^{*}\right]+k_{t 3}[S T]\left[P U^{*}\right]- \\
& k_{e 1}\left[S T^{*}\right]^{2}-k_{e 3}\left[P U^{*}\right]\left[S T^{*}\right]-k_{z 3}\left[S T^{*}\right][Z] .
\end{aligned}
$$

This system is composed of 7 equations in seven functions, together with 13 materials parameters. Looking it from a statistical point of view, this system has too many degrees of freedom; in fact we shall compare the system solutions with experiments, but the only experimental data that was collected, are relative to the functions [ST] and [PU].

Moreover, the fits of the materials constants are calibrate to obtain the best agreement with these only two sets of experimental data: in such aspects the use of so many parameters is meaningless from a statistical point of view. The intention therefore is to collect some constants, because we cannot distinguish between them in our preceding experiments [1]. So far, in the system (2-8), the following simplifying assumptions are made:

1. Do not take in account the single information on the radical species, but collect all together without distinction between them. The reason for this lies in the low concentration of the radicals with respect of monomer species; the radicals concentrations, generally, is about $10^{-4}$ times less than the initial monomer concentration. So:

$$
\left[R^{*}\right]=\left[I^{*}\right]+\left[S T^{*}\right]+\left[P U^{*}\right] .
$$

2. Collect in one propagation constant, the diffusion and transferring reactions: 


$$
\begin{aligned}
& k_{p 1}=k_{d 2}=k_{t 1}=k_{t 4} ; \\
& k_{p 2}=k_{d 3}=k_{t 2}=k_{t 3},
\end{aligned}
$$

where the constants $\mathrm{k}_{\mathrm{p} 1}$ and $\mathrm{k}_{\mathrm{p} 2}$ are referred to the species PU and ST respectively.

3. The action of $\mathrm{Z}$ is assumed to be the same for every species, so:

$$
k_{z}=k_{z 1}=k_{z 2}=k_{z 3} .
$$

4. As further simplification, assume:

$$
k_{e 1}=k_{e 2}=k_{e 3}=0 \text {, }
$$

neglecting the termination steps.

So far:

$$
\begin{aligned}
& \frac{d[I]}{d t}=-\frac{1}{2} k_{d}[I], \\
& \frac{d[P U]}{d t}=-k_{p 1}[P U]\left[R^{*}\right], \\
& \frac{d[S T]}{d t}=-k_{p 2}[S T]\left[R^{*}\right], \\
& \frac{d[Z]}{d t}=-k_{z}[Z]\left[R^{*}\right], \\
& \frac{d\left[R^{*}\right]}{d t}=-\frac{1}{2} f \cdot k_{d}[I]-k_{z}[Z]\left[R^{*}\right] .
\end{aligned}
$$

In Eq. (13) $f$ is a parameter to take in account the efficiency of the initiator, of initial value $f_{0}$, and it decreases with increasing the polymer concentration. It can be expressed as [11]:

$$
f=f_{0}^{2} \frac{\left(\frac{[M]-[M]_{\infty}}{[M]_{0}-[M]_{\infty}}\right)^{2}}{2\left(1-f_{0}\right) \frac{[I]}{[I]_{0}}}\left(1+\frac{4\left(1-f_{0}\right) \frac{[I]}{[I]_{0}}}{f_{0}^{2}\left(\frac{[M]-[M]_{\infty}}{[M]_{0}-[M]_{\infty}}\right)^{2}}-1\right)
$$


The index ${ }_{0}$ indicates the initial concentration of the species while $\mathrm{M}_{\infty}$ is the residual monomer concentration after the cure.

As simplification for M, only in Eq. 14, the expression

$$
[M]=\frac{[P U]+[S T]}{2} \text {, }
$$

has the mean of an average value of the monomers concentration. The equations (9-13) are a system composed by 5 equations in 5 functions characterised by 6 materials constants, $\mathrm{k}_{\mathrm{z}}, \mathrm{k}_{\mathrm{p} 1}, \mathrm{k}_{\mathrm{p} 2}, \mathrm{k}_{\mathrm{d}}, \mathrm{f}_{0}, \mathrm{M}_{\infty}$.

To take into account the change to a diffusion controlled mechanism, assume a functional form for the propagation constants [9]

$$
\begin{aligned}
& k_{p 1}=k_{p 01}\left(\frac{[P U]-[P U]_{\infty}}{[P U]_{0}-[P U]_{\infty}}\right)^{m 1} ; \\
& k_{p 2}=k_{p 02}\left(\frac{[S T]-[S T]_{\infty}}{[S T]_{0}-[S T]_{\infty}}\right)^{m 2} .
\end{aligned}
$$

$\mathrm{k}_{\mathrm{p} 01}$ and $\mathrm{k}_{\mathrm{p} 02}$ are constants depending on the temperature relative to PU and ST respectively.

Note that the use of equations (14-15-16), to take in account the diffusion controlled polymerisation mechanism, introduce a new parameter, $\mathbf{M}_{\infty}$; in fact when $M=M_{\infty}$ all the propagation constants are equal to 0 and the monomer conversion is stopped. This parameter takes an empirical one: the average value of the residual monomer concentration of the last $10 \%$ of our experimental data. The reason for this choice lie, once again, in the ratio between the number of parameters and the experimental curves at our disposal: if this ratio increases too much, estimation legitimacy decrease progressively.

It is well known that the curing cycle of resin is strongly influenced by the temperature. In the system (2-8), this dependence appear only in three objects. Explicitly in the $\mathrm{k}_{\mathrm{d}}$, where the activity of initiator is supposed to increase with increasing the temperature according to the equation:

$$
k_{d}=k_{d 0} e^{-\frac{E_{d}}{R T}}
$$


Moreover, also $\mathrm{k}_{\mathrm{p} 0}$ and $\mathrm{M}_{\infty}$ are dependant on the temperature [9]; this will be verified only when the estimation parameters is complete. $f_{0}$ was taken as $0.2[9,11]$, $\mathrm{k}_{\mathrm{d}}$ was experimentally measured. So far, estimated values of the five constants, $\mathrm{k}_{\mathrm{z}}, \mathrm{k}_{\mathrm{p} 01}, \mathrm{k}_{\mathrm{p} 02}, \mathrm{~m}_{1}, \mathrm{~m}_{2}$ are used.

\section{3 - Procedure to integrate equations (2-8)}

The procedure used to estimate the constants and to obtain the solution of the system (2-8) is explained.

The system is presented in normal form, as a typical Cauchy problem, with initial values. We integrate (2-8) by a standard Newton integrator supplied in Mathematica ${ }^{\circledR}$.

The accuracy of the method is limited by the machine precision, that, in single precision, is $10^{-8}$. This precision is sufficient to catch the main features of the system.

A bisection technique was employed, based on arbitrary initial values of the parameters, moved to minimise the expression;

$$
G=G_{1}+G_{2}
$$

where

$$
G_{1}=\frac{1}{N-m} \sum_{i=1}^{N}\left(\alpha_{1}-\bar{\alpha}_{1 i}\right)^{2},
$$

and

$$
G_{1}=\frac{1}{N-m} \sum_{i=1}^{N}\left(\alpha_{2}-\bar{\alpha}_{2 i}\right)^{2}
$$

i.e., the measure of "error estimation" residuals between the experimental data, $\bar{\alpha}_{1 i}$, $\bar{\alpha}_{2 i}$ and the numerical models $\alpha_{1}$ and $\alpha_{2}$. $\mathrm{N}$ is the number of experimental points and $\mathrm{m}$ is the number of parameters employed in the model to fit the data [12]. In this model they are equal to the numbers of constants to determinate, 5 . The constants were searched in the following range: 


$$
\begin{aligned}
& k_{z-\text { inf }}=1, \\
& k_{z \text {-sup }}=10^{6}, \\
& k_{p 01 \text {-inf }}=1, \\
& k_{p 01-\text { sup }}=10^{6}, \\
& k_{p 02 \text {-inf }}=1, \\
& k_{p 02 \text {-sup }}=10^{6}, \\
& m_{1 \text {-inf }}=10^{-1}, \\
& m_{1-\text { sup }}=10, \\
& m_{2 \text {-inf }}=10^{-1}, \\
& m_{2-\text { sup }}=10,
\end{aligned}
$$

where inf and sup have the mean of lower and upper limit respectively. The $k$ are expressed in $L /\left(g^{*}\right.$ mol $\left.{ }^{*} \min \right)$ while the $m$ are dimensionless.

The set of constants whose corresponding solution obtain a lower $G$ value, are fixed and the others changed. This procedure is repeated until the constant converges to a value. This method is known in the literature [13] under the name of bisection.

For an example of convergence, a plot of $\mathrm{G}$ as a function of the $\mathrm{k}_{\mathrm{p} 01}$ is showed in Fig. 1 ; here, iteratively, the solution converges to a lower $G$, which has the mean of a best fit with experimental data.

To test the validity of this procedure for each estimation we:

1) Started it with many different initial values of constants.

2) Change the order of estimation between the constants in the program during the estimation.

3) The step of bisection was changed between $1 / 2$ and $8 / 9$.

4) This procedure is repeated many times in all possible sorts of the chosen constants, always leading to the same value of the constants and G. Moreover the fittedconstant was changed between them in order to obtain a real absolute minimum of G.

The best fit set of constants were always the same. This is a necessity condition of stability of the program. 


\section{4 - Initial conditions for the system (2-8)}

The initial condition of the five functions, $[\mathrm{I}],[\mathrm{Z}],[\mathrm{ST}],[\mathrm{PU}],\left[\mathrm{R}^{*}\right]$ were chosen as follow:

$$
\begin{aligned}
& {[I]_{0}=I\left(t_{0}\right)=4.53 * 10^{-2},} \\
& {[Z]_{0}=Z\left(t_{0}\right)=1.75 * 10^{-4},} \\
& {\left[\alpha_{P E}\right]_{0}=\alpha\left(t_{0}\right)=0,} \\
& {\left[\alpha_{S T}\right]_{0}=\alpha\left(t_{0}\right)=0,} \\
& {\left[R^{*}\right]_{0}=R^{*}\left(t_{0}\right)=0,} \\
& k_{d 0}=1.7467 \cdot 10^{-18} \mathrm{sec}^{-1}, \\
& E_{d}=0.823 \mathrm{~J} / \mathrm{mol}, \\
& f_{0}=0.2 .
\end{aligned}
$$

All the concentrations are expressed in $g / \mathrm{mol}^{*} L$ and the values are the same of [1]. 


\section{3. - RESULTS}

The monomers degree of conversion, $\alpha_{1}$ and $\alpha_{2}$,together with the experimental data, $\overline{\alpha_{1}}$, and $\overline{\alpha_{2}}$, (measured in [1]) are shown in Fig. 2a-2d. In Figures 2a-2b, the values of $\alpha_{1}$ (PU) vs. time, as calculated from the numerical solutions of Eqns. 2-8 are shown together with the experimental data, $\overline{\alpha_{1}}$, and $\bar{\alpha}_{2}$. The temperatures were $336^{\circ} \mathrm{K}, 343^{\circ} \mathrm{K}$ (Fig. 2a) and $348^{\circ} \mathrm{K}, 353^{\circ} \mathrm{K}, 363^{\circ} \mathrm{K}$ (Fig. 2b). The same plot, for the ST monomer, are reported in Figures 2c-2d. The continuum curves represent the numerical solution.

These findings show the agreement between experimental data and the theory is very good. The fit is still very good at high temperatures (Fig. $2 \mathrm{~b}$ and $2 \mathrm{~d}$ ) where the approximations assumed in the model, lead to a decreased agreement.

To perform a quantitative comparison between the models used to describe the kinetic cure reactions, as in the previously paper, the Gauss coefficient as a hypothesis test was calculated. In Table 1, they are shown for the five temperature and compared with that of Ref. [1]: the lowest coefficient always belongs to the method published in this paper. This findings mean, that in spite of its higher complexity, the method presented here leads to a fit of the experimental data significantly better than the others methods. In fact, by definition, the Gauss hypothesis test was born to compare different methods taking in account the degree of freedom, i.e., the number of parameters to be fitted in the model. The kinetics of PU and ST was monitored separately.

In Figures 3-6, the functions $I(t), Z(t), R(t), f(t)$ are plotted for the five temperature. As usual, no experimental monitoring was performed on these functions.

The solution for $I(t)$ (Eqn. 2, Fig. 3) is trivial and analytically solved; it represents the exponential decay of the initiator concentration.

From Fig. 4, the decreasing concentration of inhibitor is very fast. Note that the reaction starts at a time when all the inhibitor is consumed.

The number of free radicals, $R^{*}$, is increased with increasing temperature (see Fig. 5) and is not going to zero with time, because the termination step is neglected. From Eq. 13 it is understood that the radicals concentration reaches a plateau when $[\mathrm{Z}]$ and $\mathrm{f} * \mathrm{I}]$ are very small. The efficiency of the initiator, $f$, is found to decrease with increasing time and temperature. 
It can be pointed out, after $1 / 5$ of the complete time of curing, the presence of the inhibitor, $Z$, and initiator, $I$, no longer has importance, because its value, owing to the decreasing of $f$, is quite close to zero. At this point the reaction is totally dominated by the free radicals concentration $\left[R^{*}\right]$, that is quite constant.

From the Table 1 we can note that the $\mathrm{k}_{\mathrm{p} 01}$ and $\mathrm{k}_{\mathrm{p} 02}$ values increase with increasing temperature; Figure 7 shows these values can be fitted by an Arrhenius plot, according to the following equation:

$$
\begin{aligned}
& k_{p 01}=A_{1} e^{-\frac{E_{1}}{R T}}, \\
& k_{p 02}=A_{2} e^{-\frac{E_{2}}{R T}} ;
\end{aligned}
$$

where

$$
\begin{aligned}
& \mathrm{A}_{1}=1.100510^{18} \mathrm{~L} /(\mathrm{g} \mathrm{mol} \mathrm{min}), \\
& \mathrm{A}_{2}=2.649310^{16} \mathrm{~L} /(\mathrm{g} \mathrm{mol} \mathrm{min}),
\end{aligned}
$$

The different slope, corresponds to the activation energy of the propagation reactions. Their values were found:

$$
\begin{aligned}
& \mathrm{E}_{1}=98.1 \pm 2 \mathrm{KJ} / \mathrm{mol} \\
& \mathrm{E}_{2}=110 \pm 2 \mathrm{KJ} / \mathrm{mol}
\end{aligned}
$$

The agreement of the fit is very good as can be seen from Figure 7 and the values are in agreement with the literature [7].

The constants $\mathrm{m}_{1}, \mathrm{~m}_{2}$, seem to have a general increasing trend with increasing the reaction temperature (cfr. Table 1) but no longer as the propagation constant. These results agree with Han and Lee [7].

It could be noted as the model (Eqns. 9-13) can be reduced to the Han and Lee model just posing:

$$
\begin{aligned}
& \mathrm{k}_{\mathrm{p} 01}=\mathrm{k}_{\mathrm{p} 02} \text { and } \\
& {[\mathrm{M}]=[\mathrm{PU}]+[\mathrm{ST}] .}
\end{aligned}
$$




\section{4. - CONCLUSION}

The commercial unsaturated polyesters have large utilisation owing to their characteristics and the possibility to change them by modifying the kinetic parameters.

However a complete description of the kinetic mechanism of styrene and polyester unsaturations, starting from the basic reactions, seem lacking in the literature. Many papers deal with techniques, like Differential Scanning Calorimetry, and are able to describe the overall kinetic process without distinguish between the different species involved.

Han and Lee [7] proposed a more complete description of the kinetics, solving the model in the case of only one monomer species.

In this paper a complete solution of a system able to describe the kinetic of both styrene and polyester unsaturations is proposed.

This paper measures and calculates the kinetics of ST and PU separately, instead of as one monomeric species. The advantage of this kinetic model, described by a system of differential equations, with respect to the empirical equations, lies in a better understandment of the kinetics mechanism, together with a better fit of the experimental data. Moreover the method can be expanded if a more refined analysis is required. The equations were numerically solved and the parameters fitted to the best fit of the experimental data, by the bisection method, to minimise the Gauss coefficient.

The solution show excellent agreement with the experimental data that was proposed in a previous paper. The solutions show the reaction, after a while, is totally regulated by the concentration of the free radicals; moreover, according to the literature, the reaction only starts after the inhibitor is quite totally consumed. The decreasing of the initiator concentration, together with its lost efficiency, enhanced this result.

The concentration of free radicals seem to reach a plateau, owing to the absence of a termination step, which was neglected to simplify the system

Finally the calculation of the statistical parameters shows how, quantitatively, this solution obtains a better fit, when compared with both traditional empirical equations and a new one that was proposed in a previous paper.

This system can be reduced, by some simplifying, to the system proposed by Han and Lee by neglecting any distinction between the styrene monomers and the PU. 


\section{- Acknowledgements}

The author thank Dr. P. Musto and Dr. G. Rotoli for fruitful discussions and their friendly criticism. 


\section{REFERENCES:}

1. R. dell'Erba et al, Polym. Neworks \& Blends, 7, 1-11 (1997).

2. Y.S. Houng and L.J. Lee, Macromolecules, 20, 1490 (1987)

3. Y.S. Houng and J.S. Lee, Polymer,34, 295 (1993)

4. Y.S. Houng and C.J. Chen, J. Appl. Polym. Sci, 46, 1573 (1992)

5. C.D. Han and H.W. Lem, Polym. Engn. Sci, 24, 473, (1984)

6. C.D. Han and H.W. Lem, Polym. Engn. Sci, 29, 1879, (1984)

7. C.D. Han and H.W. Lem, Polym. Engn. Sci, 33, 2859, (1987)

8. H. Horie et al., J. Polym. Sci A-1, 8, 2839 (1979)

9. M.R. Kamal et al., SDE, Tech. Pop., 19, 187 (1973)

10. M.R. Kamal and Sourour, Polym. Engn. Sci., 13, 59 (1973)

11.J.S. Biesenberger and D.H. Sebastian "Principles of Polymerisation Engineering", Wiley, N.Y. 1983

12. E. W. H. Press et sl., “Numerical recipes”, Cambridge Univ. Press, Cambridge 1986. 


\section{Figure Captions}

1. Gauss coefficient, $\mathrm{G}$, Vs. propagation constant $\mathrm{k}_{\mathrm{p} 01}$ in optimisation process; $\mathrm{T}=348^{\circ} \mathrm{K}$.

2. Conversion degree Vs time together with the numericals solutions for the investigated temperatures. Fig. 2a) for styrene, ST, :A) $336^{\circ} \mathrm{K}$; B) $343^{\circ} \mathrm{K}$.

Fig. 2b) C) $348^{\circ} \mathrm{K}$; D) $353^{\circ} \mathrm{K}$; E) $363^{\circ} \mathrm{K}$.

Fig. 2c) for poliester unsaturation, PU, :A) $336^{\circ} \mathrm{K}$; B) $343^{\circ} \mathrm{K}$.

Fig. 2d) C) $348^{\circ} \mathrm{K}$; D) $353^{\circ} \mathrm{K}$; E) $363^{\circ} \mathrm{K}$.

3. Analytical solutions of the initiator concentration for the investigated temperatures. A) $336^{\circ} \mathrm{K}$; B) $343^{\circ} \mathrm{K}$; C) $348^{\circ} \mathrm{K}$; D) $353^{\circ} \mathrm{K}$; E) $363^{\circ} \mathrm{K}$.

4. Numerical solutions of the inhibitor, concentration, [Z], for the investigated temperatures. A) $336^{\circ} \mathrm{K}$; B) $343^{\circ} \mathrm{K}$; C) $348^{\circ} \mathrm{K}$; D) $353^{\circ} \mathrm{K}$; E) $363^{\circ} \mathrm{K}$.

5. Numerical solutions of the radicals concentration, $\left[R^{*}\right]$, for the investigated temperatures. A) $336^{\circ} \mathrm{K}$; B) $343^{\circ} \mathrm{K}$; C) $348^{\circ} \mathrm{K}$; D) $353^{\circ} \mathrm{K}$; E) $363^{\circ} \mathrm{K}$.

6. Numerical solutions of the initiator efficiency, f, for the investigated temperatures. A) $336^{\circ} \mathrm{K}$; B) $343^{\circ} \mathrm{K}$; C) $348^{\circ} \mathrm{K}$; D) $353^{\circ} \mathrm{K}$; E) $363^{\circ} \mathrm{K}$.

7. Arrhenius plots relative to the propagation constants, $\mathrm{k}_{\mathrm{p} 01} \square$, and $\mathrm{k}_{\mathrm{p} 02} \bullet$. 


\begin{tabular}{|c|c|c|c|c|c|c|c|c|}
\hline Temperature $\left({ }^{\circ} \mathbf{K}\right)$ & $\begin{array}{l}\mathbf{k}_{\mathrm{z}} \\
\left(\mathrm{L} / \mathrm{g}^{*} \mathrm{~mol} * \mathrm{~min}\right)\end{array}$ & $\begin{array}{l}\mathbf{k}_{\mathrm{p} 01} \\
\left(\mathrm{~L} / \mathbf{g}^{*} \mathrm{~mol} * \mathrm{~min}\right)\end{array}$ & $\begin{array}{l}\mathbf{k}_{\mathrm{p} 02} \\
(\mathrm{~L} / \mathrm{g} * \mathrm{~mol} * \mathrm{~min})\end{array}$ & $\mathbf{m}_{1}$ & $\mathbf{m}_{2}$ & $\begin{array}{l}G_{a} * 10^{3} \\
{[1]}\end{array}$ & $\begin{array}{l}\mathrm{G}_{\mathrm{b}} * 10^{3} \\
{[1]}\end{array}$ & $\mathrm{G}^{*} 10^{3}$ \\
\hline 336 & 126.83 & 8.70 & 7.17 & 1.72 & 1.74 & 0.36 & 24.10 & 0.15 \\
\hline 343 & 1881.04 & 46.64 & 35.77 & 1.61 & 1.64 & 0.35 & 17.09 & 0.16 \\
\hline 348 & 704.52 & 68.97 & 65.28 & 1.95 & 2.16 & 0.47 & 35.05 & 0.30 \\
\hline 353 & 1541.07 & 50.96 & 57.31 & 1.77 & 1.94 & 0.50 & 37.34 & 0.28 \\
\hline 363 & 39.68 & 172.67 & 172.98 & 2.77 & 3.26 & 1.60 & 88.67 & 0.83 \\
\hline
\end{tabular}

Table 1: Values of the constants fitted for the five temperature. Gauss coefficient relative to this paper are showed in the last column. In columns 7 and 8 are showed the Gauss coefficients taken from [1], for the model a and b (empirical equations) respectively. 


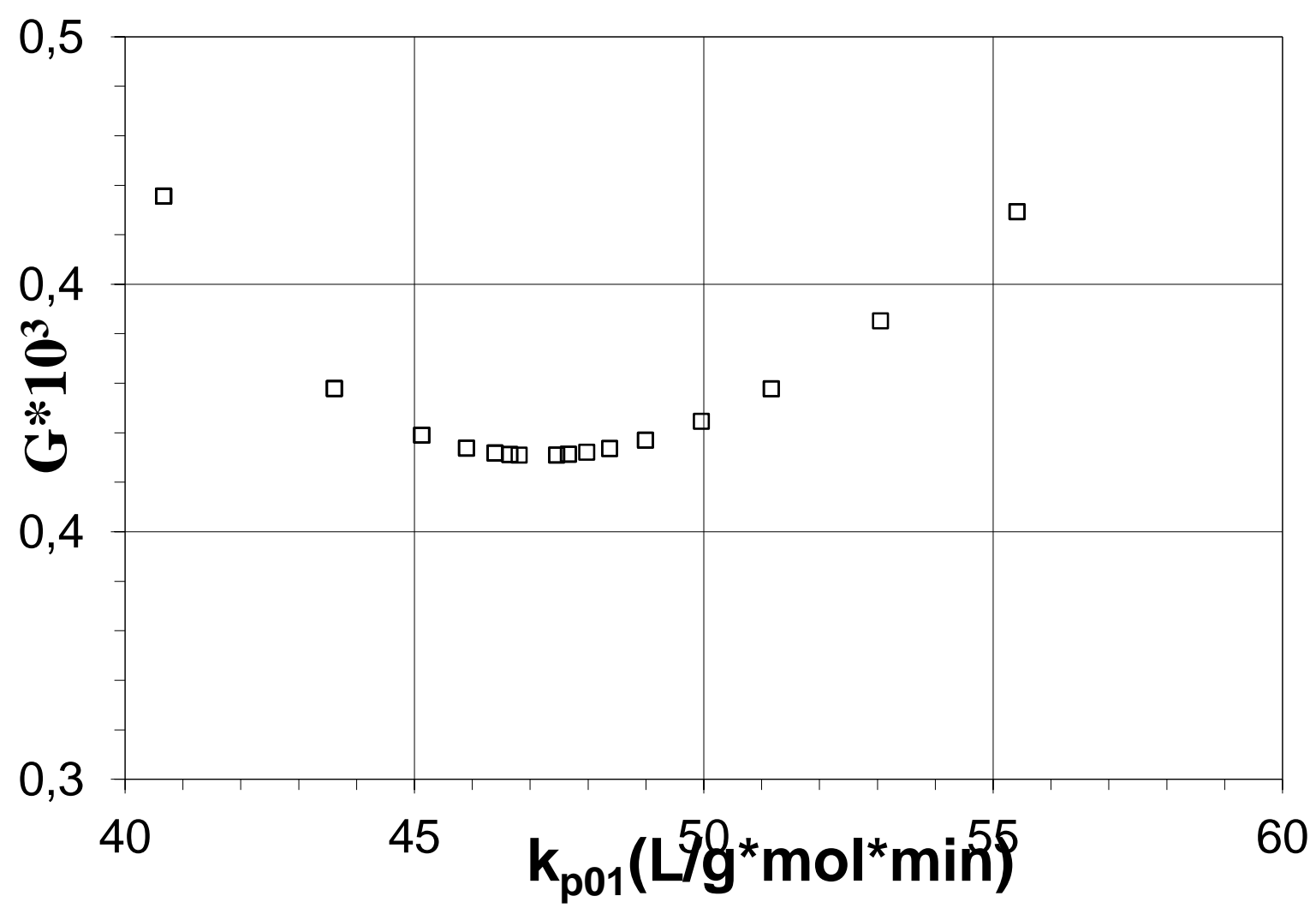

1. Gauss coefficient, G, Vs. propagation constant $\mathrm{k}_{\mathrm{p} 01}$ in optimisation process; $\mathrm{T}=348^{\circ} \mathrm{K}$. 


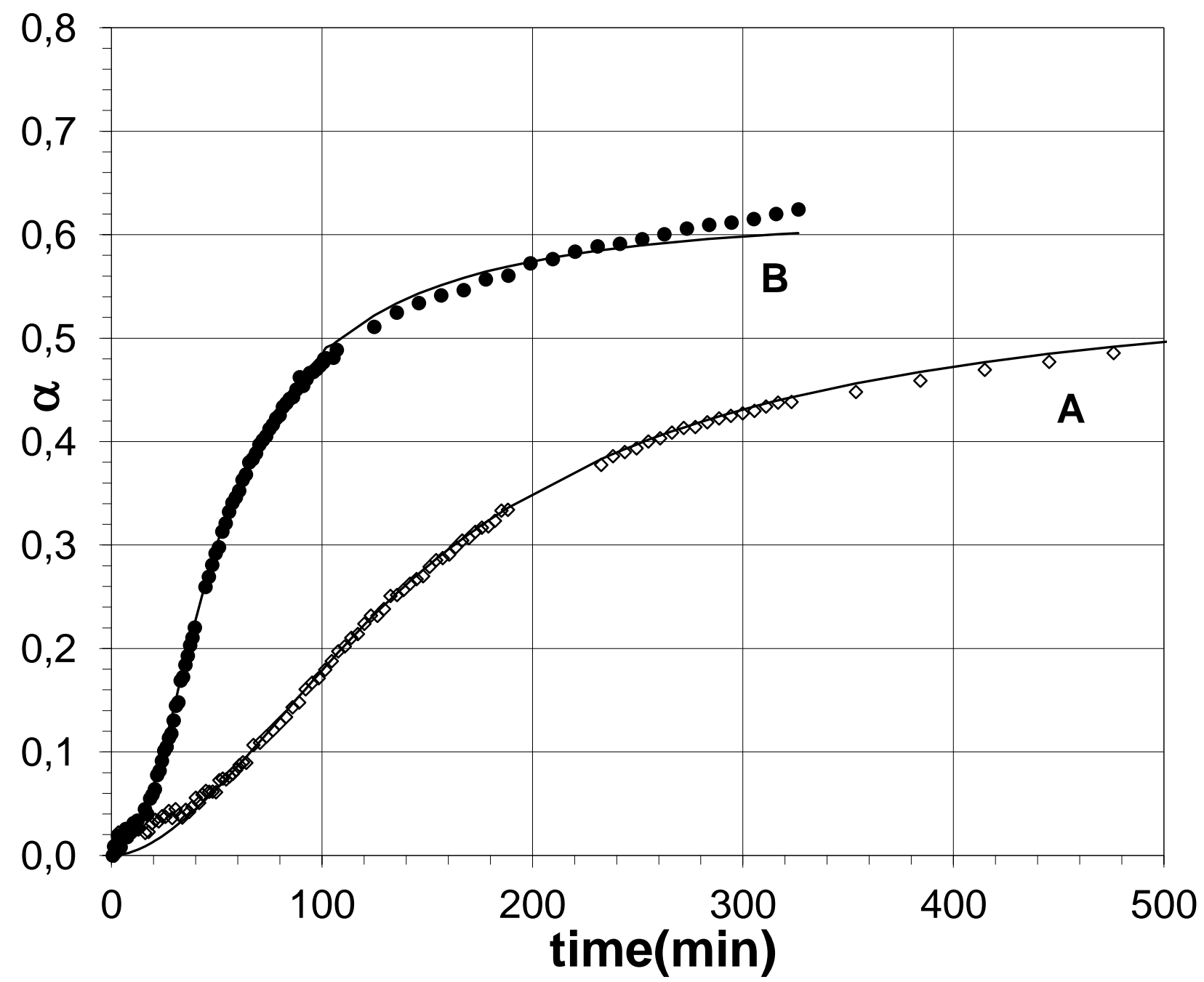




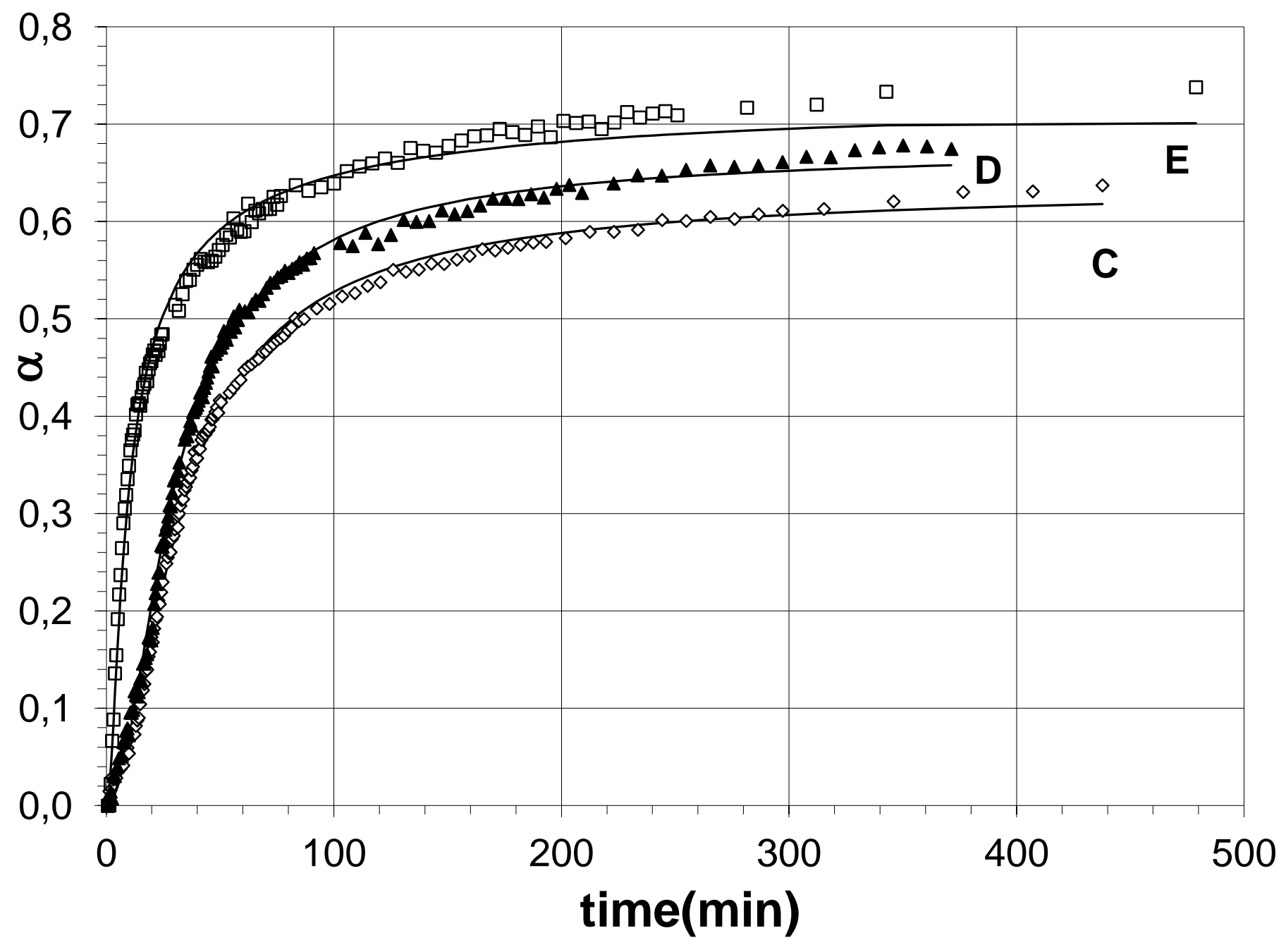




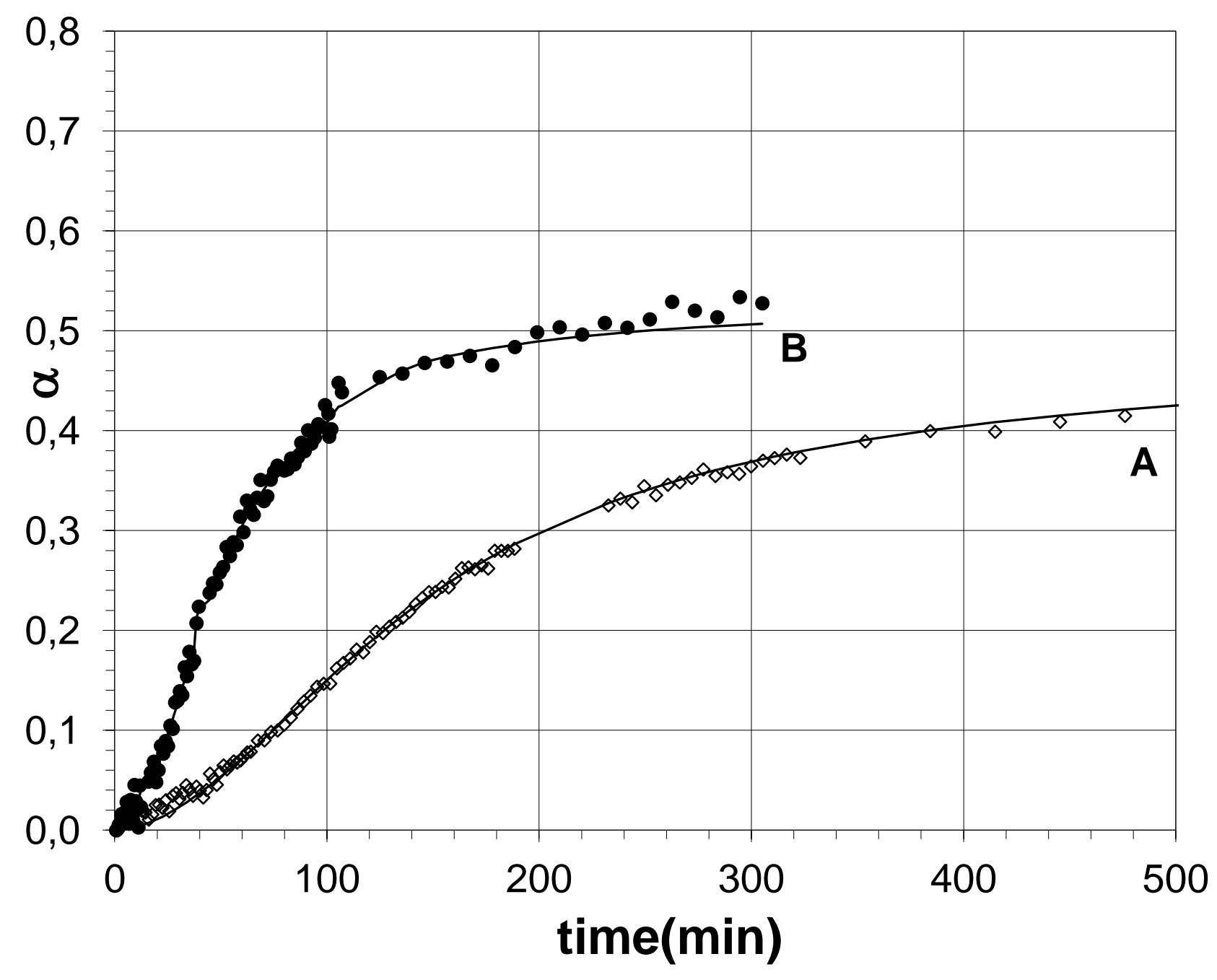




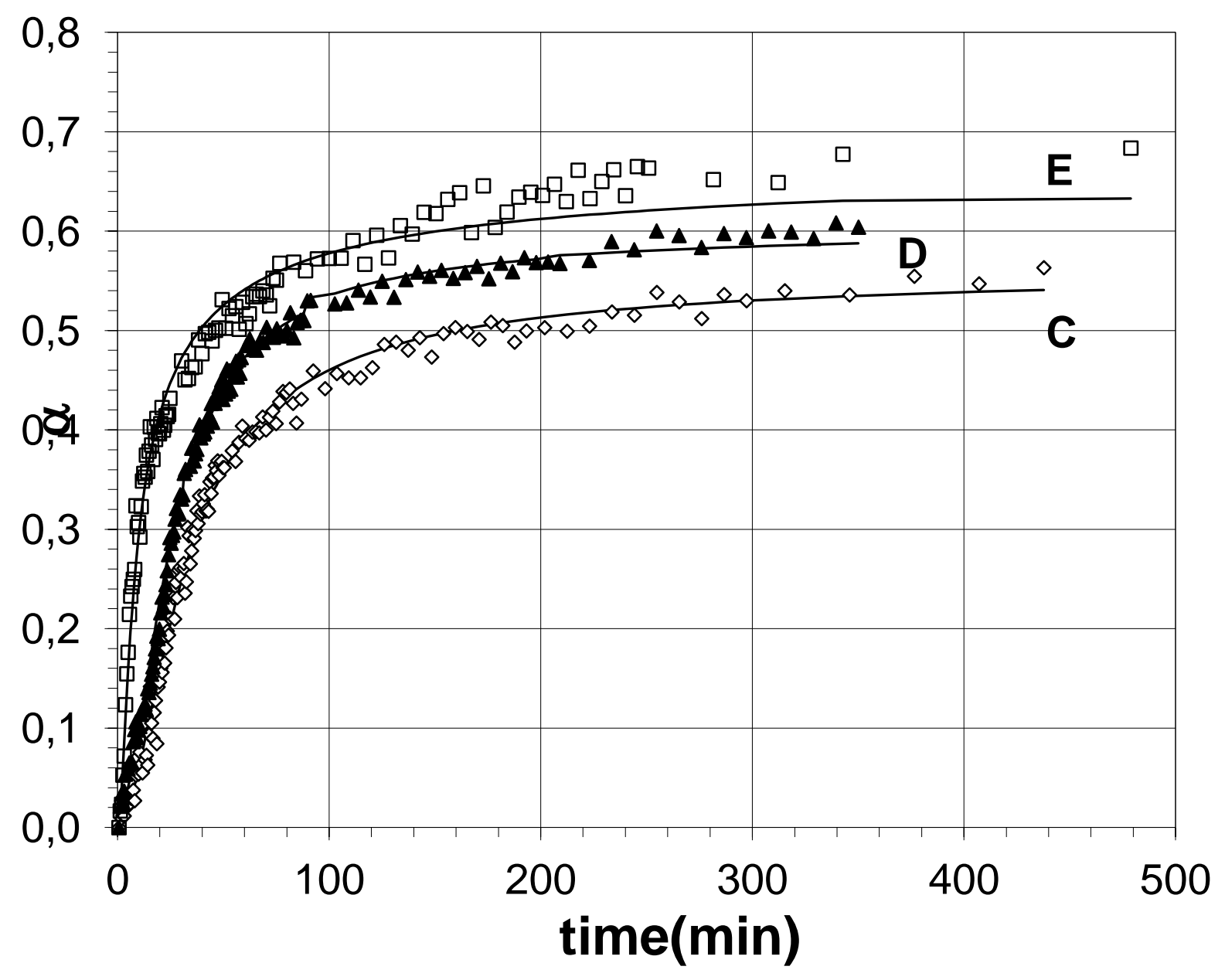


2. Conversion degree Vs time together with the numericals solutions for the investigated temperatures. $336^{\circ} \mathrm{K}$; B) $343^{\circ} \mathrm{K}$. Fig. 2b) C) $348^{\circ} \mathrm{K}$; D) $353^{\circ} \mathrm{K}$; E) $363^{\circ} \mathrm{K}$.

Fig. 2c) for poliester unsaturation, PU, :A) $336^{\circ} \mathrm{K}$; B) $343^{\circ} \mathrm{K}$. Fig. 2d) C) $348^{\circ} \mathrm{K}$; D) $353^{\circ} \mathrm{K}$; E) $363^{\circ} \mathrm{K}$. 


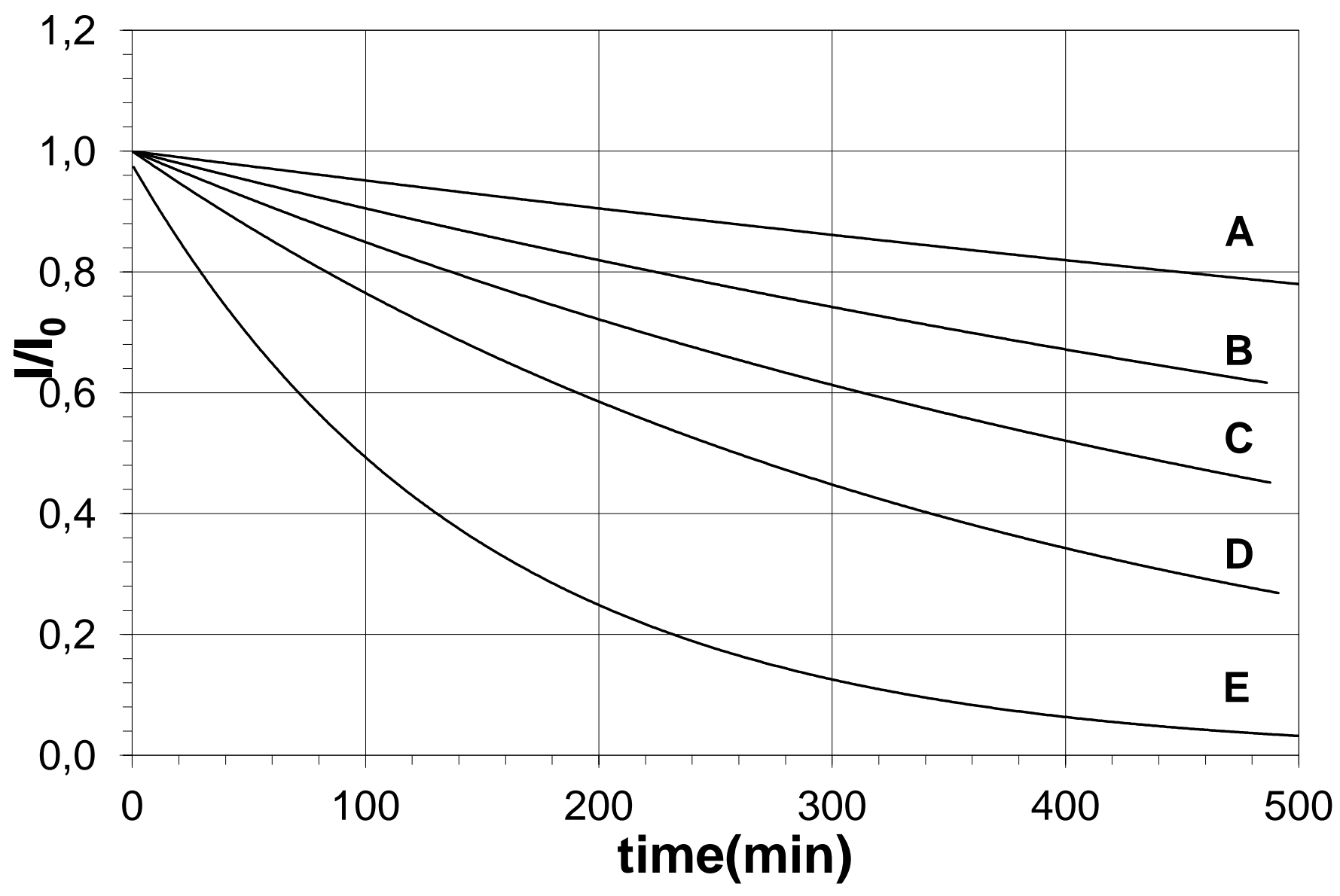

3. Analytical solutions of the initiator concentration for the investigated temperatures. A) $336^{\circ} \mathrm{K}$; B) $343^{\circ} \mathrm{K}$; $\left.\mathrm{C}\right) 348^{\circ} \mathrm{K}$; $\mathrm{D}$ ) $353^{\circ} \mathrm{K}$; $\mathrm{E}$ ) $363^{\circ} \mathrm{K}$. 


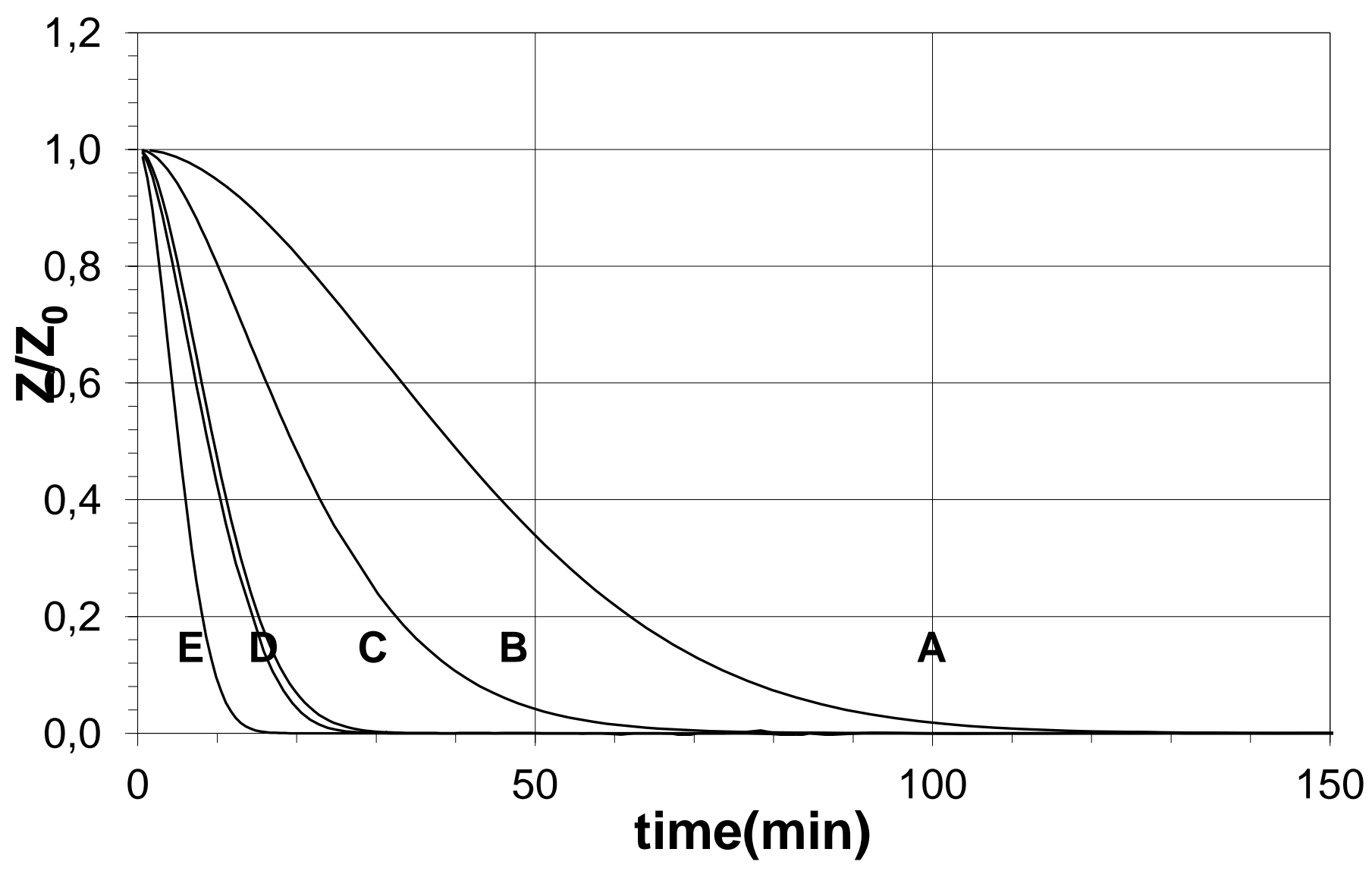

4. Numerical solutions of the inhibitor, concentration, [Z], for the investigated temperatures. A) $336^{\circ} \mathrm{K}$; B) $343^{\circ} \mathrm{K}$; $\left.\mathrm{C}\right) 348^{\circ} \mathrm{K}$; $\mathrm{D}$ ) $353^{\circ} \mathrm{K}$; E) $363^{\circ} \mathrm{K}$. 


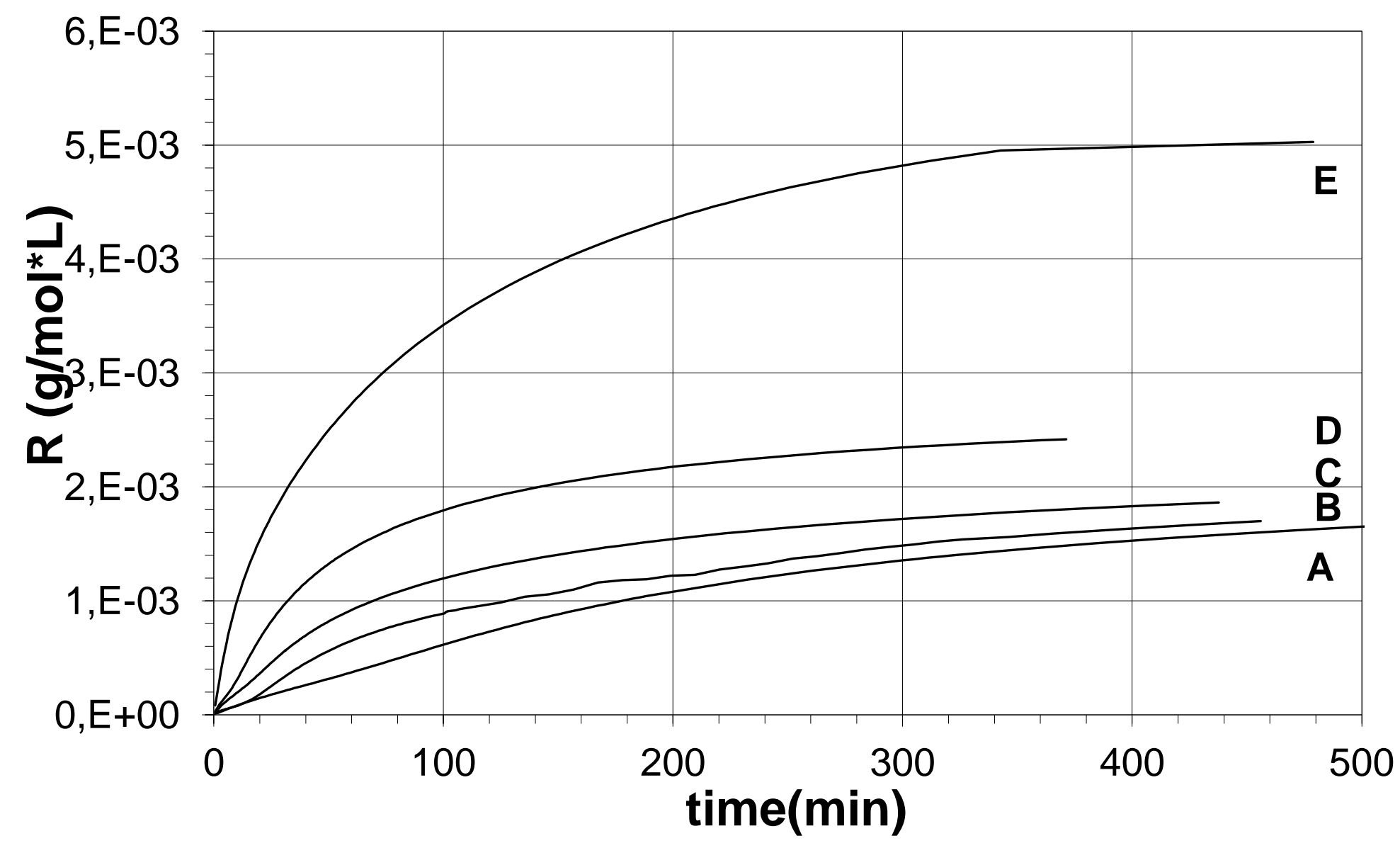

5. Numerical solutions of the radicals concentration, [R*], for the investigated temperatures. A) $336^{\circ} \mathrm{K}$; $\mathrm{B}$ ) $343^{\circ} \mathrm{K}$; $\left.\mathrm{C}\right) 348^{\circ} \mathrm{K}$; $\mathrm{D}$ ) $353^{\circ} \mathrm{K}$; E) $363^{\circ} \mathrm{K}$. 


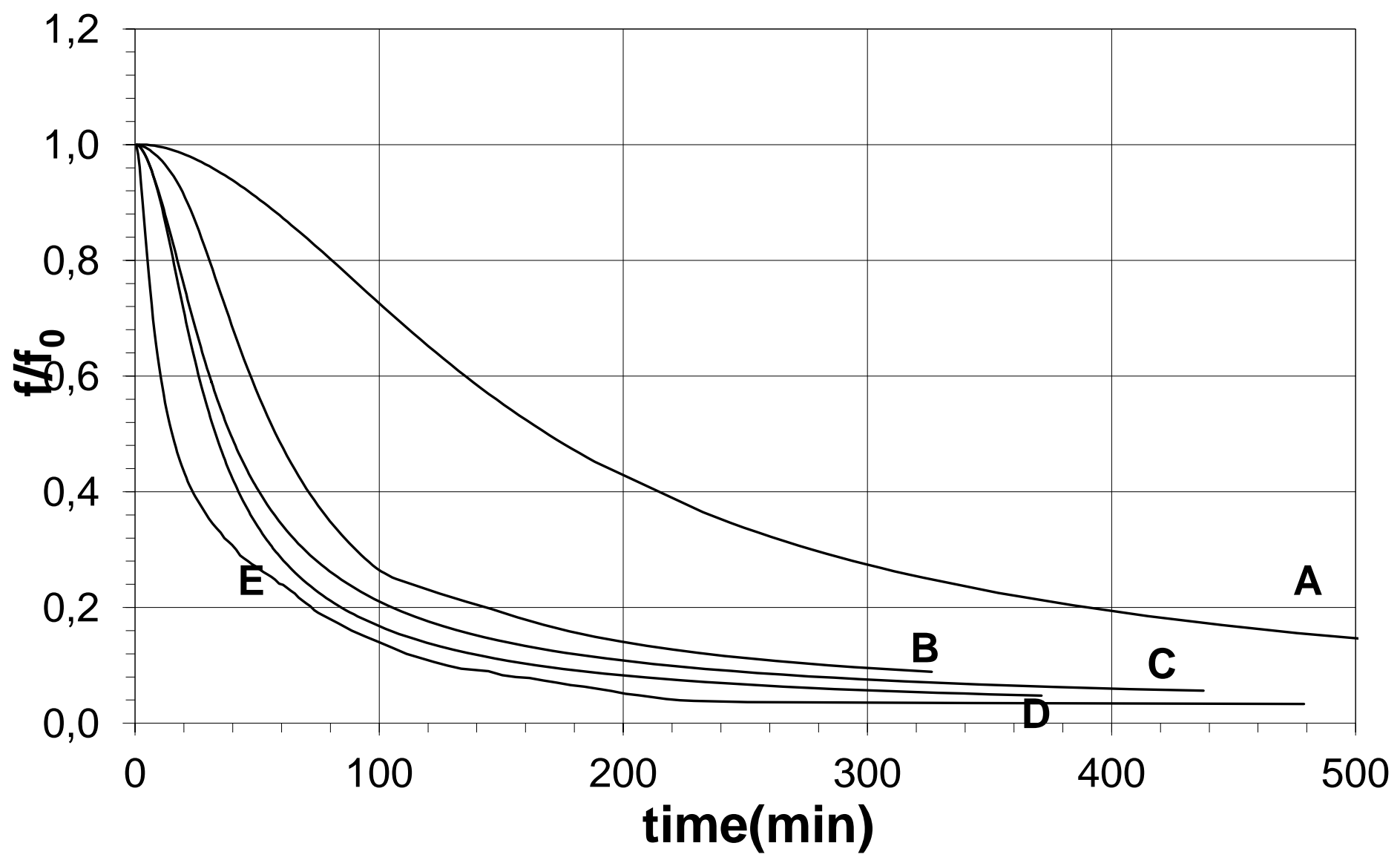

6. Numerical solutions of the initiator efficiency, f, for the investigated temperatures. A) $336^{\circ} \mathrm{K}$; $\mathrm{B}$ ) $343^{\circ} \mathrm{K}$; C) $348^{\circ} \mathrm{K}$; $\mathrm{D}$ ) $353^{\circ} \mathrm{K}$; $\mathrm{E}$ ) $363^{\circ} \mathrm{K}$ 


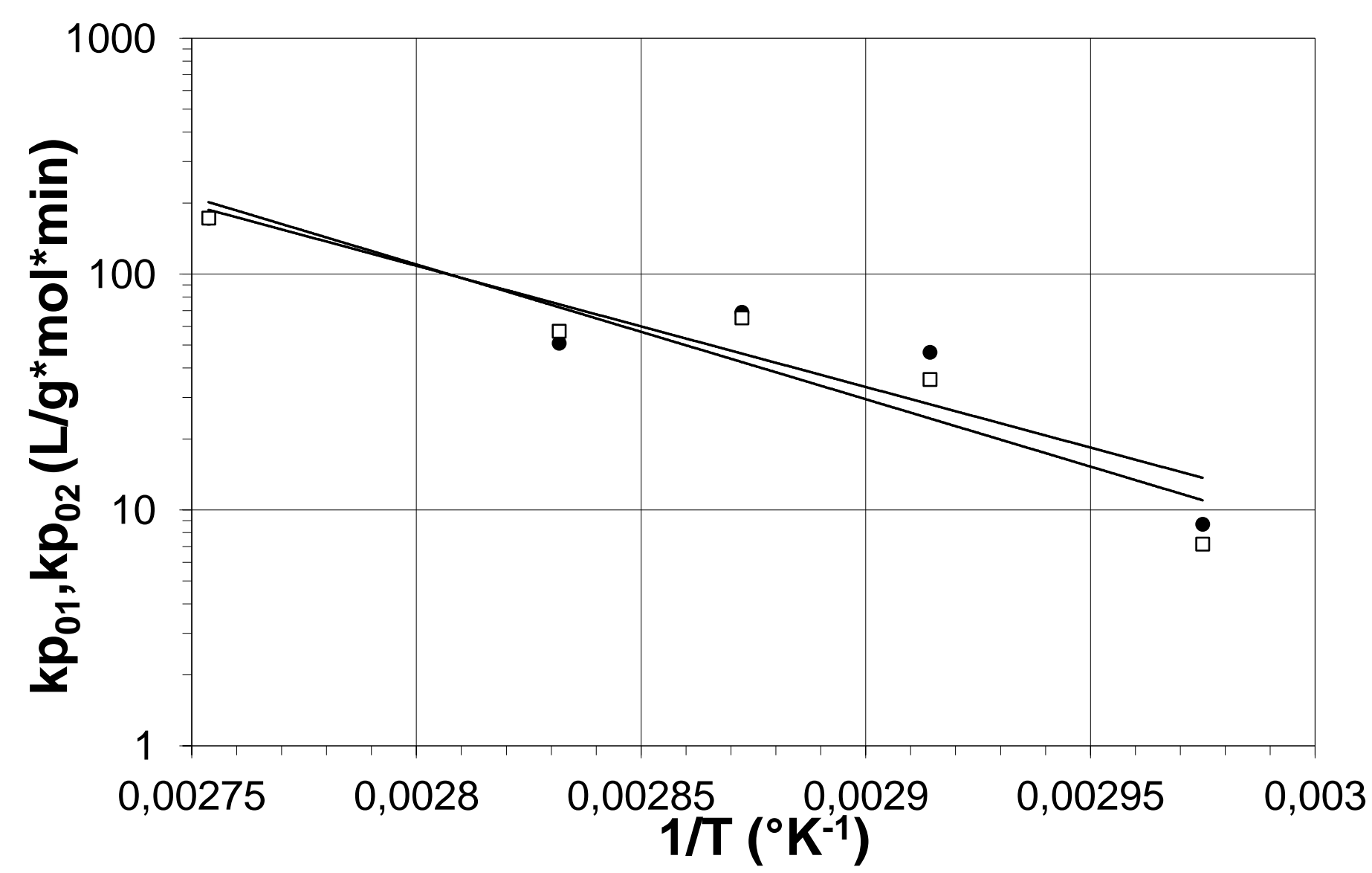

7. Arrhenius plots relative to the propagation constants, $\mathrm{k}_{\mathrm{p} 01} \square$, and $\mathrm{k}_{\mathrm{p} 02} \bullet$. 